\title{
Candida albicans biofilm formation on peptide functionalized polydimethylsiloxane
}

Kristof De Prijck ${ }^{\mathrm{a}}$, Nele De Smet ${ }^{\mathrm{b}}$, Monika Rymarczyk-Machal ${ }^{\mathrm{b}}$, Gonzalez Van

5 Driessche $^{c}$, Bart Devreese ${ }^{c}$, Tom Coenye ${ }^{\mathrm{a}}$, Etienne Schacht ${ }^{\mathrm{b}}$ and Hans J. Nelis ${ }^{\mathrm{a} *}$

${ }^{a}$ Laboratory of Pharmaceutical Microbiology, Ghent University, Harelbekestraat 72, B-9000,

Ghent, Belgium; ${ }^{b}$ Laboratory of Polymer Chemistry and Biomaterials, Ghent University, Krijgslaan 281 S4bis, B-9000, Ghent, Belgium; ${ }^{c}$ Laboratory for Protein Biochemistry and 10 Biomolecular Engineering, Ghent University, K.L. Ledeganckstraat 35, B-9000, Ghent, Belgium

*Corresponding author

Tel: +32 (0) 92648091

15 Fax: +32 (0) 92648195

Email address: Hans.Nelis@UGent.be 


\begin{abstract}
In order to prevent biofilm formation by Candida albicans, several cationic peptides were covalently bound to polydimethylsiloxane. The salivary peptide Histatin 5 and two synthetic variants (Dhvar 4 and Dhvar 5) were used to prepare peptide functionalized PDMS using 45 azido-2,3,5,6-tetrafluoro-benzoic acid (AFB) as an interlinkage molecule. In addition, polylysine-, polyarginine- and polyhistidine-PDMS surfaces were prepared. Dhvar 4 functionalized PDMS yielded the highest reduction of the number of C. albicans biofilm cells in the Modified Robbins Device. Amino acid analysis demonstrated that the amount of peptide immobilized on the modified disks was in the nanomole range. Poly-D-lysine PDMS,

10 in particular the homopeptides with low molecular weight $(2,500$ and 9,600) showed the highest activity against C. albicans biofilms, with reductions of $93 \%$ and $91 \%$, respectively. The results indicate that the reductions are peptide dependent.
\end{abstract}

Keywords: biofilm, Candida albicans, peptide, grafting, Modified Robbins Device 


\section{Introduction}

Biofilm formation on medical devices is frequently associated with infections and in many cases removal of the medical device is the only option to combat them (Khardori and Yassien 1995; Kadry et al 2009). Several approaches have already been evaluated to inhibit microbial biofilm formation on medical materials (Danese 2002; Von Eiff et al 2005). First, various materials have been passively coated e.g. alkanethiols on gold (Hou et al 2007), fish protein coatings on glass or vinyl plastic coverslips (Vejborg and Klemm 2008) and diamond-like carbon on stainless steel (Raulio et al 2008). These passive coatings are not antimicrobially active but alter the physico-chemical properties of surfaces, so that micro-organism/substrate interactions are weakened or even prevented (Hetrick and Schoenfish 2006). However, their effectiveness is limited, due to adsorption of conditioning films, masking the functional groups (Hetrick and Schoenfish 2006). Secondly, coatings releasing antimicrobial compounds including antibiotics (Price et al 1996; Kwok et al 1999a, 1999b; Stigter et al 2004), silver ions (Dowling et al 2003) or silver nanoparticles and antiseptics (for a review see Von Eiff et al 2005) have been designed for use in intravenous polyurethane catheters and urinary catheters (Wu and Grainger 2006). A third series of surface modifications includes polymers with positively charged moieties such as quaternary ammonium or phosphonium groups at their surface. These substrates can be synthesized via copolymerization (Kenawy and Mahmoud 2003; Kenawy et al 2006; Kenawy et al 2007) or using photo- or plasma-induced graft polymerization (Hsiue et al 1998; De Smet et al., unpublished data). Grafting results in the production of materials with altered surface properties without influencing the bulk properties (Pan et al 2003).

Covalent binding of cationic peptides may be a useful approach to prevent microbial biofilm formation. Histatins are a family of naturally occurring, histidine-rich, low molecular weight peptides in human saliva (Helmerhorst et al 1997) and tear fluid (Jumblatt et al 2006). 
Of these, histatin (Hst) 1, 3 and 5 are the most abundant peptides in saliva (De Smet and Contreras 2005). Hst 5, which is a peptide fragment derived from Hst 3, possesses the highest activity against Candida albicans and salivary concentrations range from 15 to $50 \mu \mathrm{M}$ (Edgerton et al 1998). In the oral cavity, salivary peptides are believed to inhibit C. albicans

5 overgrowth, thus offering a natural protection from oropharyngeal candidiasis. In addition, homodimerization of histatin-derived peptides showed an improved in vitro bactericidal activity against Staphylococcus aureus (Welling et al 2007). Dhvar 4 and Dhvar 5 are synthetic variants of the active domain of Hst 5 (Den Hertog et al 2004). Exposure of microorganisms to histatins results in leakage of intracellular components accompanied by a release 10 of intracellular potassium and a decrease in the cellular ATP-level.

In certain circumstances, disease states can diminish the body's natural protective mechanisms against infection. For example, malignant laryngeal tumors of the vocal cords in humans are removed by a total laryngectomy. For voice rehabilitation of laryngectomized patients, a voice prosthesis (VP) is placed between the trachea and the oesophagus 15 (Kasperbauer and Thomas 2004). This VP is highly susceptible to colonization by microorganisms, particularly by Candida spp., growing in biofilms on the surface (Bauters et al 2002; Elving et al 2002). Laryngectomized patients show a decreased salivary secretion as a side effect of radiation therapy, thus reducing the concentration of natural protective peptides (Rodrigues et al 2006). The release of antimycotics from buccal, bio-adhesive tablets has not been successful in preventing biofilm formation on VPs because of this reduced saliva secretion (Ameye et al 2005). In vitro studies have already focussed on the removal of mixed species biofilms by Dhvar 4 and 5 (Oosterhof et al 2003). However, the antibiofilm effect against C. albicans by peptides (applied by covalent binding, unlike by adsorption or dip coating) completely immobilized on silicone rubber has not been determined so far. 
In the present study, the antifungal effect of three histatin-like antimicrobial peptides (Hst 5, Dhvar 4 and Dhvar 5) and several polylysine, polyarginine and polyhistidine homopolymers covalently bound to silicone was assessed against planktonic and sessile $C$. albicans cells.

\section{Materials and methods}

\section{Materials}

Dhvar 4 and Dhvar 5 were synthesized at the Mousseron Institute (Montpellier, France).

HEPES buffer, MES buffer, ethyl acetate, 1-ethyl-3-(3-dimethylaminopropyl) carbodiimide hydrochloride (EDC), N-hydroxysuccinimide (NHS), acrylic acid (AA) and Hst5 were purchased from Sigma (St. Louis, MO, USA). Ethanol was obtained from Chem Lab (Zedelgem, Belgium). 4-azido-2,3,5,6-tetrafluorobenzoic acid (AFB) was purchased from Invitrogen (Carlsbad, CA, USA) and RBS 35 solution was purchased from Chemical Products

15 (Brussels, Belgium). Dichloromethane was obtained from Acros Fine Chemicals (Geel, Belgium). All homopolymers were purchased from Sigma. They included seven poly-Dlysine $\mathrm{HBr}$ salts (molecular weight distributions: 1,000-4,000; 4,000-15,000; 15,000-30,000; 30,000-70,000; 70,000-150,000; 150,000-300,000 and > 300,000); four poly-L-lysine $\mathrm{HBr}$ salts (molecular weight distributions: 500-2,000; 1,000-5,000; $\geq 15,000$ and 15,000-30,000); two poly-DL-lysine $\mathrm{HBr}$ salts (molecular weight distributions: 1,000-4,000; 25,000-40,000); three poly-L-arginine $\mathrm{HCl}$ salts (molecular weight distributions: 5,000-15,000; 15,000-70,000 and $>$ 70,000 ) and one poly-L-histidine $\mathrm{HCl}$ salt (molecular weight distribution: 5,00025,000). 
Medical grade silicone rubber (Q7-4735, Dow Corning Corp., Midland, MI, USA) was prepared as described previously (Coenye et al 2008).

\section{Synthesis of PDMS functionalized with peptides}

5 To select the appropriate interlinkage molecule for covalent binding of peptides to PDMS, Dhvar 4 was bound onto the PDMS surface by grafting of AA or AFB. To initiate grafting of PAA onto PDMS, the surfaces were brought in contact with a benzophenone solution (5\% $[\mathrm{w} / \mathrm{v}]$ in ethanol). In a first approach, Dhvar 4 was coupled to the carboxylic groups of grafted AA using EDC as coupling reagent in combination with NHS. To this end, a stable activated ester on the PDMS surface was prepared by soaking the PAA-grafted PDMS surface for $4 \mathrm{~h}$ at room temperature in a solution of $1.76 \mathrm{mM}$ EDC and $1.78 \mathrm{mM}$ NHS, dissolved in MESbuffer ( $\mathrm{pH}$ 5.5). The surfaces were washed in MES-buffer for $24 \mathrm{~h}$ at $37^{\circ} \mathrm{C}$. Finally the terminal amino group of Dhvar 4 was coupled onto the surface in HEPES buffer $\mathrm{pH}$ 8.5, resulting in covalent binding of Dhvar 4 onto PDMS. After a contact time of $48 \mathrm{~h}$ the peptide containing disks were rinsed in sterile MilliQ water and treated aseptically until use.

The second approach to synthesize Dhvar 4-PDMS makes use of AFB. PDMS sheets were incubated in ethanol for $4 \mathrm{~h}$, to remove the catalyst and subsequently cleaned in a $2 \%$ (v/v) RBS solution. The sheets were incubated in a saturated AFB solution $(5 \mathrm{mg} / \mathrm{ml})$ prepared in dry ethyl acetate for $4 \mathrm{~h}$, allowing AFB to adsorb onto the PDMS sheets. Afterwards the incubated sheets were dried under reduced pressure to remove ethyl acetate from the surface. The azido group of AFB readily reacts with methyl groups on the PDMS and both sides of the PDMS sheet were irradiated with UVC light $(\lambda=254 \mathrm{~nm})$ for 5 min. Following polymerization, the surfaces were cleaned using dichloromethane to remove the non-reacted AFB. NHS esters were then synthesized by the reaction of the carboxylic group with EDC and NHS in MES-buffer $\mathrm{pH} 5.5$ for $4 \mathrm{~h}$ at room temperature. The obtained surfaces 
were cleaned in MES buffer for $24 \mathrm{~h}$ at $37^{\circ} \mathrm{C}$. Finally, Dhvar 4 was coupled to the PDMS substrate as described above.

For covalent binding of all other (homo)peptides, the coupling procedure with AFB was used. Peptide concentrations of 5 or $20 \mathrm{mg} / \mathrm{ml}$ and 1 or $5 \mathrm{mg} / \mathrm{ml}$ were used for Dhvar 4 and Dhvar 5, respectively. The peptide concentration for covalent binding of Hst 5 was 0.5 $\mathrm{mg} / \mathrm{ml}$. All homopolymers were bound to PDMS using a concentration of $5 \mathrm{mg} / \mathrm{ml}$ of the homopeptide.

\section{Characterization of modified PDMS surfaces}

10 The peptide modified PDMS surfaces were characterized using Attenuated Total ReflectionInfrared spectroscopy (ATR-IR) and Attenuated Total Reflection-imaging (ATR-imaging)

Attenuated Total Reflection-Infrared spectroscopy (ATR-IR) measurements on the modified PDMS surfaces were performed at room temperature using a Biorad 575C spectrometer. All spectra were recorded between $4000 \mathrm{~cm}^{-1}$ and $720 \mathrm{~cm}^{-1}$ at $2 \mathrm{~cm}^{-1}$ resolution.

A single beam reference spectrum of a freshly cleaned diamond crystal was recorded before the measurements and used as the background spectrum. All spectra were normalized by the C-H bending band of the PDMS backbone located at $1259 \mathrm{~cm}^{-1}$.

For Attenuated Total Reflection-imaging (ATR-imaging) the Spotlight 300 instrument (Perkin Elmer Life and Analytical Sciences, Waltham, MA, USA), was used. Samples of 1.5 mm thickness were tightened between the sample stage and the Ge crystal. The Spotlight system was run with two scans per pixel and with a spectral resolution of $4 \mathrm{~cm}^{-1}$. The data collection software collects rectangular image areas of $100 \mu \mathrm{m}$ by $100 \mu \mathrm{m}$ (De Smet et al., unpublished data). 
Amino acid analyses were carried out to determine the amount of cationic peptide bound to PDMS. To this end, the peptide modified PDMS disks were cut in two pieces and introduced in a vial for hydrolysis. The vials were loaded in a vessel filled with $200 \mu \mathrm{l} 6 \mathrm{~N}$ $\mathrm{HCl}$ and subsequently with argon, closed and incubated at $106^{\circ} \mathrm{C}$ for $24 \mathrm{~h}$. The hydrolysed amino acids were washed from the polymer with $200 \mu \mathrm{l}$ of MilliQ water. From this mixture, 5 $\mu \mathrm{l}$ of sample was loaded on an automated Applied Biosystems amino acid analyzer using the phenylisothiocyanate chemistry. Each sample was measured in triplicate.

\section{Strain and culture conditions}

Candida albicans SC5314 (ATCC MYA-2879) was used throughout. The strain was maintained at $-80^{\circ} \mathrm{C}$ using the Microbank storage system (Pro-Lab Diagnostics, Richmond Hill, ON, Canada). After thawing at room temperature, one bead was transferred to $10 \mathrm{ml}$ of a sterile Sabouraud broth (Becton Dickinson Co, Franklin Lakes, NJ, USA) and the inoculated broth was incubated at $37^{\circ} \mathrm{C}$ for $24 \mathrm{~h}$. From this suspension, a pure culture was obtained on Sabouraud Dextrose agar (SDA, (Becton Dickinson). To prepare overnight cultures, one or two isolated colonies of the pure culture were transferred to Sabouraud broth.

\section{Determination of the minimal inhibitory concentration}

The minimal inhibitory concentrations (MICs) were determined using LYM broth (5 mM $\mathrm{KCl}, 5.6 \mathrm{mM} \mathrm{Na}_{2} \mathrm{HPO}_{4}, 0.5 \mathrm{mM} \mathrm{MgSO}_{4}, 1.0 \mathrm{mM}$ sodium citrate, $0.4 \mathrm{mg} \mathrm{l}^{-1} \mathrm{ZnCl}_{2}, 2.0 \mathrm{mg} \mathrm{l}^{-1}$ $\mathrm{FeCl}_{3} \cdot 6 \mathrm{H}_{2} \mathrm{O}, 0.1 \mathrm{mg} \mathrm{l}^{-1} \mathrm{CuSO}_{4} .5 \mathrm{H}_{2} \mathrm{O}, 0.1 \mathrm{mg} \mathrm{l}^{-1} \mathrm{MnSO}_{4} \cdot \mathrm{H}_{2} \mathrm{O}$ and $\left.0.1 \mathrm{mg} \mathrm{l}^{-1} \mathrm{Na}_{2} \mathrm{~B}_{4} \mathrm{O}_{7} \cdot 10 \mathrm{H}_{2} \mathrm{O}\right)$ according to Rothstein et al (2001). Glucose, an amino acid mixture, and a vitamin mixture were added as well according to the manufacturer's instructions. Stock solutions of each peptide were diluted (1:2). Of each dilution, two ml were transferred to the wells of a flat-

25 bottom 24-well microtiter plate (TPP, Trasadingen, Switzerland). A standardized cell 
suspension was prepared as follows : overnight cultures were centrifuged and the cells of these freshly prepared overnight cultures were washed three times with and diluted in LYM broth to a concentration of $10^{6} \mathrm{CFU} \mathrm{ml}$. One hundred $\mu \mathrm{l}$ of these standardized cell suspensions, containing appr. $10^{5}$ C. albicans cells per ml LYM broth, were added to each well. Prior to use, the bacterial suspensions were vigorously mixed using a vortex mixer. Following $24 \mathrm{~h}$ of incubation at $37^{\circ} \mathrm{C}$, the growth was measured by determining the absorbance at $530 \mathrm{~nm}$ using a Wallac Victor ${ }^{2}$ (PerkinElmer Life and Analytical Sciences, Waltham, MA, USA) microtiter plate reader. The MICs for each peptide was defined as the lowest concentration resulting in a lack of visible growth. For the homopeptides, instead of LYM broth, Yeast Nitrogen Base (YNB) medium supplemented with $50 \mathrm{mM}$ glucose was used. Each MIC test was carried out in triplicate. The following concentration ranges were tested : 125-0.12 $\mu \mathrm{g} / \mathrm{ml}$ (Dhvar 4), 100-0.01 $\mu \mathrm{g} / \mathrm{ml}$ (Dhvar 5), 850-0.001 $\mu \mathrm{g} / \mathrm{ml}$ (Hst), 2500$78 \mu \mathrm{g} / \mathrm{ml}$ (poly-DL-lysine) and 2500-1 $\mu \mathrm{g} / \mathrm{ml}$ (poly-L-lysine, poly-DL-lysine and poly-Larginine).

\section{Biofilm growth in the MRD}

C. albicans biofilms were grown on PDMS disks in the Modified Robbins Device (MRD), as described previously (Coenye et al 2008). Prior to the determination of the antibiofilm effect, all the modified surfaces were rinsed in sterile saline $(0.9 \%[\mathrm{w} / \mathrm{v}]$ sodium chloride solution).

A flow system consisting of 6 custom made stainless steel Modified Robbins Devices (MRDs) was employed to allow C. albicans adhesion and subsequent biofilm formation. One such a device comprises six individual ports in a linear array along a channel of rectangular cross-section, having dimensions of $10.0 \mathrm{~mm}$ (width), $145.0 \mathrm{~mm}$ (length) and $3.5 \mathrm{~mm}$ (depth), respectively. Each port may hold a cylinder-shaped plug that serves as a substrate for biofilm development at the interior side of the MRD. These were placed in an aluminium heating 
block to ensure a constant temperature of $37^{\circ} \mathrm{C}$ during biofilm growth. Prior to each run the tubing, the valves and the devices were cleaned with MilliQ water and finally autoclaved. The assembly of these different parts was carried out prior to sterilization. Two bottles containing the C. albicans inoculum suspension and the growth medium (YNB supplemented with 50 $\mathrm{mM}$ glucose) were connected to the silicone tubing under aseptic conditions. The inoculum suspension was prepared using saline ( $0.9 \%$ sodium chloride solution). To this end $C$. albicans overnight cultures were centrifuged at $4000 \mathrm{rpm}$ for $4 \mathrm{~min}$ and the pelleted yeasts were washed with saline. The cells were subjected to three wash cycles and finally resuspended in saline. One $\mathrm{ml}$ aliquots were added to $99 \mathrm{ml}$ saline containing bottles resulting in the inoculum suspensions. The growth medium was prepared by adding $6.7 \mathrm{~g}$ of Yeast Nitrogen Base (Becton Dickinson) and $9 \mathrm{~g}$ glucose to $100 \mathrm{ml}$ of MilliQ water. This solution was sterilized by vacuum filtration through a $0.45 \mu \mathrm{m}$ cellulose acetate membrane filter (Corning Incorporated, Corning, NY, USA) and was aseptically diluted (1:10) in sterile MilliQ water, resulting in a YNB solution with final glucose concentration of $50 \mathrm{mM}$. The tubing was mounted on top of a pump head in a peristaltic pump (Watson-Marlow 505S, Bredel, Wilmington, MA, USA). The setup of each device includes a bypass to allow rinsing of the silicone tubing with either inoculum suspension or growth medium at the inlet side and removal of entrapped air bubbles. First the inoculum suspension was pumped towards the MRDs in order to fill the interior side of the MRD. Once filled, the pump was switched off and the MRDs were clamped off using a clamp at the inlet and one at the outlet side. Each device was flipped over to allow planktonic C. albicans cells adhering to the disks. After $1 \mathrm{~h}$, the MRDs were flipped back and the clamps were loosened. The pump was started to permit a flow of continuous growth passing over the colonized disks. Flow rate was set at $0.5 \mathrm{rpm}$ (corresponding with $7.9 \mathrm{ml} / \mathrm{h}$ ) and C. albicans biofilms were allowed to develop at $37^{\circ} \mathrm{C}$ for $24 \mathrm{~h}$. 
After biofilm formation, the number of sessile C. albicans cells was determined by plating on SDA, as described previously (Coenye et al 2008). To this end, the sessile C. albicans cells were harvested following $1 \mathrm{~h}$ of adhesion and $1 \mathrm{~h}$ of adhesion followed by $24 \mathrm{~h}$ of biofilm formation. The disks were aseptically recovered from the plug (MRD) and added to Sab. The cells were harvested by $30 \mathrm{~s}$ of intensive mixing with a vortex (IKA ${ }^{\circledR}$ works, Inc., Wilmington, NC, USA) and $30 \mathrm{~s}$ of sonication (Bransonic ${ }^{\circledR} 3510$, Soest, The Netherlands) three times. Finally the C. albicans cell suspensions were serially (1:10) diluted in Sab, one ml aliquots were transferred to petri dishes (Novolab, Geraardsbergen, België) and mixed with molten SDA $\left(45^{\circ} \mathrm{C}\right)$. The plates were incubated at $37^{\circ} \mathrm{C}$ for $24 \mathrm{~h}$, the number of colonies was counted and the number of colony forming units was calculated for all disks.

\section{Statistical analysis}

All cell counts were log transformed and data from the peptide modified disks were compared with those from the corresponding control disks. Analysis of variance with the Scheffe post hoc tests was performed using the SPSS 15.0 software package (SPSS Inc, Chicago, IL). Differences in biofilm cell counts between modified and control disks were considered significant when $\mathrm{p}<0.05$. Correlation between molecular weight of peptides and MIC values was determined using Kendall's tau test ; correlations were considered statistically significant if $\mathrm{p}<0.05$. 


\section{Results and Discussion}

\section{Characterization of modified PDMS surfaces}

The distribution of the cationic peptides bound to the PDMS surface, studied by ATR-

5 Imaging was found to be homogeneous for both procedures, i.e. grafting of AA or AFB (see Figure 1 in Supplementary Data). However, after biofilm growth in the MRD visual inspection revealed a marked swelling (i.e. increase in surface area available for biofilm formation) of the AA grafted PDMS. In contrast, PDMS disks modified with AFB remained unchanged. This observation strongly indicates the need for the selection of the appropriate interlinkage molecules for covalent binding of antimicrobials on PDMS. For all further experiments, AFB was used as the interlinkage molecule.

\section{Antifungal effect on planktonic C. albicans cells}

The MIC of Dhvar 4, Dhvar 5 and Hst 5 for C. albicans SC5314 was $7 \mu \mathrm{M}, 9 \mu \mathrm{M}$ and $41 \mu \mathrm{M}$, respectively (Table 1). The MICs of poly-D-lysine, poly-L-lysine, poly-DL-lysine and polyL-arginine where inversely correlated with the molecular weight of each peptide $(\mathrm{p}<0.05)$ (Table 2).

\section{Antifungal effect of salivary peptides on sessile C. albicans cells}

Table 1 lists the percent reduction in sessile C. albicans cell numbers on PDMS functionalized with Dhvar 4, using AA and AFB as interlinkage molecules. The reduction for each type of modification and for each replicate was calculated with reference to the cell count on the peptide-free control PDMS disks. The cell counts on the unmodified disks ranged from $10^{4}$ to $10^{5}$ after $1 \mathrm{~h}$ of adhesion and from $10^{6}$ to $10^{7}$ following $1 \mathrm{~h}$ of adhesion and $24 \mathrm{~h}$ of biofilm formation. The results clearly show that the highest reductions in the 
numbers of sessile C. albicans cells, both after adhesion and biofim development were obtained for Dhvar 4 containing surfaces, modified using AFB. Dhvar 5 and Hst 5 yielded reductions of $64 \%$ and $72 \%(p<0.05)$. Although a 10-fold higher concentration was used in the procedure for covalent binding of Dhvar 5 compared to Hst 5, similar reductions were observed. Maximum reduction (95 \%) was obtained on Dhvar 4-PDMS surfaces.

Our results differ from those obtained by others, such as Oosterhof et al. (2003), who used an artificial throat (a biofilm model system similar to the MRD) to grow mixed species biofilms on intact Groningen button voice prostheses. They examined the biofilm eradication effect of the synthetic peptides, Dhvar 4 and Dhvar 5, applied by dip coating. After a 3-day growth period, mature biofilms were exposed 3 times a day to Dhvar 4 and Dhvar 5, dissolved in the salivary substitute Xialine in a final concentration of $4 \mathrm{mg}$ per $\mathrm{ml}$ (well above the MIC). Dhvar 4 did not affect the number of bacteria and yeasts compared with the control prostheses. The highest reductions [78 \% (bacteria) and $94 \%$ (yeasts)] were obtained on VPs soaked in Dhvar 5 solutions, (Oosterhof et al 2003). This is unlike our own observations and may reflect the profound difference in activity between bound and free peptides.

\section{Antifungal effect of homopeptides on sessile C. albicans cells}

Histatins reportedly have intracellular targets (mitochondria). Their effects on cytoplasmatic membranes are limited and permeabilization of the microbial membrane is a secondary effect rather than the primary cause of their antimicrobial activity (Ruissen et al 2001, 2002; Den Hertog et al 2005, Welling et al 2007). The most potent anti-Candida member of this family is Hst 5 and analysis of its sequence showed the presence of lysine and arginine residues (Helmerhorst et al 1997). Covalent binding of peptides only consisting of lysine, arginine and histidine residues might increase the anti-Candida effect on biofilms, as these cationic amino acids are believed to be partly responsible for the antifungal effect. 
Poly-D-lysine PDMS with molecular weights of 2,500 or 9,600 and poly-DL-lysine PDMS (molecular weight of 32,800) yielded a significantly lower C. albicans sessile cell count than the controls, with reductions of $93 \%, 91 \%$ and $79 \%$, respectively (Table 2). However, covalent binding of poly-D-lysine moieties containing more lysine residues drastically decreased the antibiofilm activity. C. albicans biofilm formation on other substrates was hardly affected (Table 2). In addition, neither poly-L-arginine PDMS nor polyL-histidine PDMS affected C. albicans biofilm growth. These observations demonstrate that inhibition of $C$. albicans biofilm formation highly depends on the nature of the immobilized peptide, its molecular weight and its stereochemistry.

\section{Conclusions}

In the present study we have shown that salivary peptides and homopeptides can be bound to PDMS using preferably AFB as the interlinkage molecule. AA is less suitable as interlinkage molecule as it results in swelling of the PDMS after contact with aqueous media in the MRD. This highlights the importance of the interlinkage molecule to be bound to PDMS.

Although reductions of $>90 \%$ (Dhvar 4 and low molecular weight poly-D-lysine) were obtained in an in vitro biofilm model system, it remains to be established if these would be sufficient for a prolonged, protective effect in vivo.

\section{Acknowledgements}

This work was supported by the Belgian Federation against Cancer and FWO-Vlaanderen. Bart Devreese is indebted to Belspo for support in the framework of an interuniversity 25 attraction pole (P6/19 IAP). The authors are indebted to Dr. Martinez (Mousseron Institute, 
Montpellier, France) for the synthesis of Dhvar 4 and Dhvar 5. They also thank Philomain Wauters and Mario Podevijn from the Technical Workshop of the Faculty of Science for the construction of an optimized and miniaturized version of the MRD.

\section{References}

Ameye D, Honraet K, Loose D, Vermeersch H, Nelis H, Remon JP. 2005. Effect of a buccal bioadhesive nystain tablet on the lifetime of a Provox ${ }^{\mathrm{TM}}$ silicone tracheoesophageal voice prosthesis. Acta Oto-Laryngol 125: 304-306.

Bauters TGM, Moerman M, Vermeersch H, Nelis HJ. 2002. Colonization of voice prostheses by albicans and non-albicans Candida species. Laryngoscope 112: 708-712.

Coenye T, De Prijck K, De Wever B, Nelis HJ. 2008. Use of the modified Robbins device to study the in vitro biofilm removal efficacy of NitrAdine ${ }^{\mathrm{TM}}$, a novel disinfecting formula for the maintenance of oral medical devices. J Appl Microbiol 105: 733-740.

Danese PN. 2002. Antibiofilm approaches: Prevention of catheter colonization. Chem Biol 9: 873-880.

De Smet K, Contreras R. 2005. Human antimicrobial peptide: defensins, cathelicidins and histatins. Biotechnol Lett 27: 1337-1347.

Den Hertog AL, Van Marle J, Van Veen HA, van 't Hof W, Bolscher JGM, Veerman ECI , Amerongen AVN. 2005. Candidacidal effects of two antimicrobial peptides: histatin 5 causes small membrane defects, but LL-37 causes massive diruption of the cell membrane. Biochem J 388: 689-695.

Den Hertog AL, Wong Fong Sang HW, Kraayenhof R, Bolscher JGM, van 't Hof W, Veerman ECI , Amerongen AVN. 2004. Interactions of histatin 5 and histatin 5-derived 
peptides with liposome membranes: surface effects, translocation and permeabilization. Biochem J 379: 665-672.

Dowling DP, Betts AJ, Pope C, McConnell ML, Eloy R, Arnaud MN. 2003. Anti-bacterial silver coatings exhibiting enhanced activity through the addition of platinum. Surf Coat Tech 163-164: 637-640.

Edgerton M, Koshlukova SE, Lo TE, Chrzan BG, Straubinger RM, Raj PA. 1998. Candidacidal activity of salivary histatins. J Biol Chem. 273: 20438-20447.

Elving GJ, van der Mei HC, van Weissenbruch R, Busscher HJ, Albers FWJ. 2002. Comparison of the microbial composition of voice prosthesis biofilms from patients requiring frequent versus infrequent replacement. Ann Otol Rhinol Laryngol 111: 200203.

Helmerhorst EJ, van 't Hof W, Veerman ECI, Simoons-Smit I, Amerongen AVN. 1997. Synthetic histatin analogues with broad-spectrum antimicrobial activity. Biochem J 326: 39-45.

Hetrick EM, Schoenfisch MH. 2006. Reducing implant-related infections: active release strategies. Chem Soc Rev 35: 780-789.

Hou S, Burton EA, Simon KA, Blodgett D, Luk YY, Ren D. 2007. Inhibiting Escherichia coli biofilm formation by self-assembled monolayers of functional alkanethiols on gold. Appl Environ Microbiol 73: 4300-4307.

Hsiue GH, Lee SD, Chang PCT, Kao CY. 1998. Surface characterization and biological properties study of silicone rubber membrane grafted with phospholipid as biomaterial via plasma induced graft copolymerization. J Biomed Mater Res 42: 134-147.

Jumblatt MM, Imbert Y, Young Jr WW, Foulks GN, Steele PS, Demuth DR. 2006. Glycoprotein 340 in normal human ocular surface tissues and tear film. Infect Immun 74: 4058-4063. 
Kadry AA, Fouda SI, Shibl AM, Abu El-Asrar AA. 2009. Impact of slime dispersants and anti-adhesives on in vitro biofilm formation of Staphylococcus epidermidis on intraocular lenses and on antibiotic activities. J Antimicrob Chemother 63: 480-484.

Kasperbauer JL, Thomas JE. 2004. Voice rehabilitation after near-total laryngectomy. Otolaryngol Clin N Am 37: 655-677.

Khardori N, Yassien M. 1995. Biofilms in device-related infections. J Ind Microbiol 15: 141147.

Kenawy ER, Abdel-Hay FI, Abou El-Magd A, Mahmoud, Y. 2006. Biologically active polymers: VII. Synthesis and antimicrobial activity of some crosslinked copolymers with quaternary ammonium and phosphonium groups. React Funct Polym 66: 419-429.

Kenawy ER, Mahmoud YAG. 2003. Biologically active polymers: Synthesis and antimicrobial activity of some linear copolymers with quaternary ammonium and phosphonium groups. Macromol Biosci 3: 107-116.

Kenawy ER, Worley SD, Broughton R. 2007. The chemistry and applications of antimicrobial polymers: a state-of-the-art review. Biomacromolecules 8: 1359-1384.

Kwok CS, Wan C, Hendricks S, Bryers JD, Horbett TA, Ratner BD. 1999a. Design of infection-resistant antibiotic-releasing polymers: I. Fabrication and formulation. J Control Release 62: 289-299.

Kwok CS, Wan C, Horbett TA, Ratner BD. 1999b. Design of infection-resistant antibioticreleasing polymers: II. Controlled release of antibiotics through a plasma-deposited thin film barrier. J Control Release 62: 301-311.

Oosterhof JJH, Elving GJ, Stokroos I, Amerongen AVN, Van der Mei HC, Busscher HJ, van Weissenbruch R, Albers FW. 2003. The influence of antimicrobial peptides and mucolytics on the integrity of biofilms consisting of bacteria and yeasts as affecting voice prosthetic air flow resistances. Biofouling 19: 347-353. 
Pan B, Viswanathan K, Hoyle CE, Moore RB. 2004. Photoinitiated grafting of maleic anhydride onto polypropylene. J Polym Sci Pol Chem 42: 1953-1962.

Price JS, Tencer AF, Arm DM, Bohach GA. 1996. Controlled release of antibiotics from coated orthopedic implants. J Biomed Mater Res 30: 281-286.

5 Raulio M, Järn M, Ahola J, Peltonen J, Rosenholm JB, Tervakangas S, Kolehmainen T, Narko P, Salkinoja-Salonen M. 2008. Microbe repelling coated stainless steel analysed by field emission scanning electron microscopy and physicochemical methods. J Ind Microbiol Biotechnol 35: 751-760.

Rodrigues L, Banat IM, Teixeira J, Oliveira R. 2006. Strategies for the prevention of microbial biofilm formation on silicone rubber voice prostheses. J Biomed Mater Res B Appl Biomater 81: 358-370.

Rothstein DM, Spacciapoli P, Tran LT, Xu T, Roberts FD, Dalla Serra M, Buxton DK, Oppenheim FG, Friden P. 2001. Anticandida activity is retained in P-113, a 12-aminoacid fragment of histatin 5. Antimicrob Agents Chemother 45: 1367-1373.

Ruissen ALA, Groenink J, Helmerhorst EJ, Walgreen-Weterings E, van 't Hof W, Veerman ECI, Amerongen AVN. 2001. Effects of histatin 5 and derived peptides on Candida albicans. Biochem J 356: 361-368.

Ruissen ALA, Groenink J, van ‘t Hof W, Walgreen-Weterings E, van Marle J, van Veen HA, Voorhout WF, Veerman ECI, Amerongen AVN. 2002. Histatin 5 and derivatives: their localization and effects on the ultra-structural level. Peptides 23: 1391-1399.

Stigter M, Bezemer J, de Groot K, Layrolle P. 2004. Incorporation of different antibiotics into carbonated hydroxyapatite coatings on titanium implants, release and antibiotic efficacy. $\mathrm{J}$ Control Release 99: 127-137.

Vejborg RM, Klemm P. 2008. Blocking of bacterial biofilm formation by a fish protein coating. Appl Environ Microbiol 74: 3551-3558. 
Von Eiff C, Kohnen W, Becker K, Jansen B. 2005. Modern strategies in the prevention of implant-associated infections. Int J Artif Organs 28: 1146-1156.

Welling MM, Brouwer CJPM, van 't Hof W, Veerman ECI, Amerongen AVN. 2007. Histatin-derived monomeric and dimeric synthetic peptides show strong bactericidal activity towards (Multi-drug resistant) Staphylococcus aureus in vivo. Antimicrob Agents Chemother 51: 3416-3419.

Wu P, Grainger DW. 2006. Drug/device combinations for local drug therapies and infection prophylaxis. Biomaterials 27: 2450-2467. 
Table 1. Reduction in C. albicans biofilm cells grown in the MRD recovered from peptide grafted PDMS.

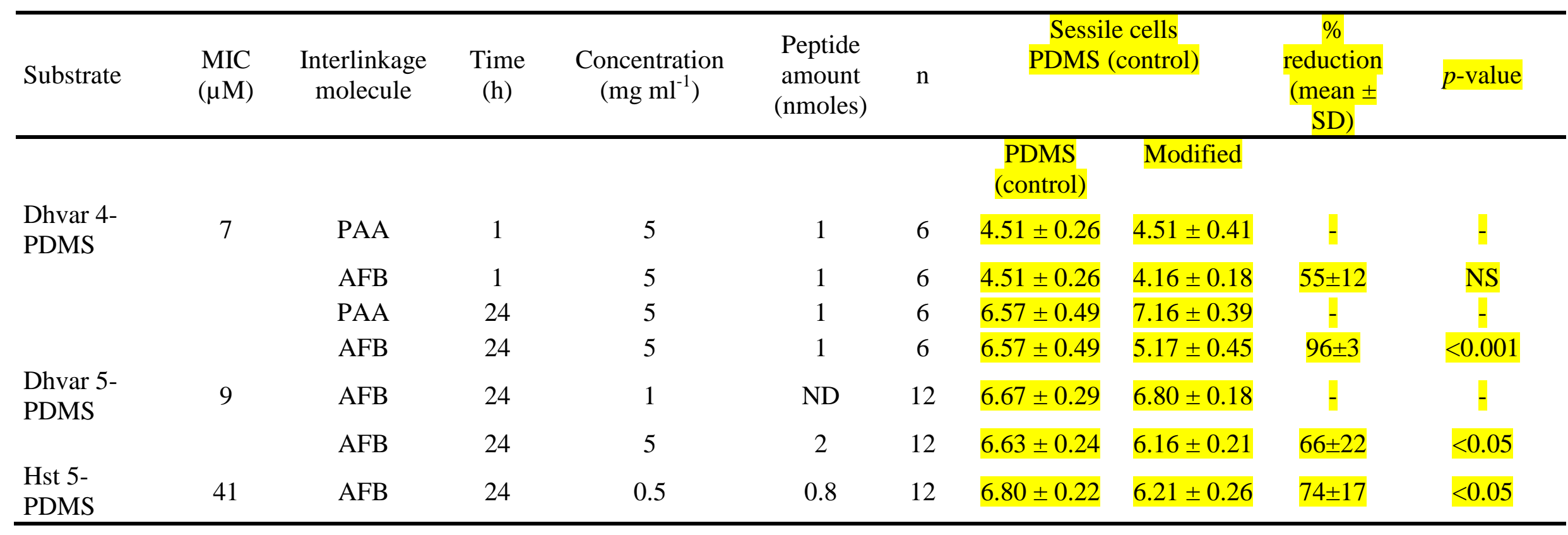

n, number of disks tested; PAA, polyacrylic acid; AFB, azido tetrafluorobenzoate; PDMS, polydimethylsiloxane; ND : not determined; Concentration refers to the concentration in solution used for modification; the amount of peptide refers to total amount per disk; - : biofilm 5 formation stimulated (i.e. cell counts on control disks lower than on modified disks) ; NS, not significant.. 
Table 2. Reduction in C. albicans biofilm cells grown in the MRD recovered from homopeptide grafted PDMS (using $5 \mathrm{mg} \mathrm{ml}^{-1}$ of petide and AFB as interlinkage molecule).

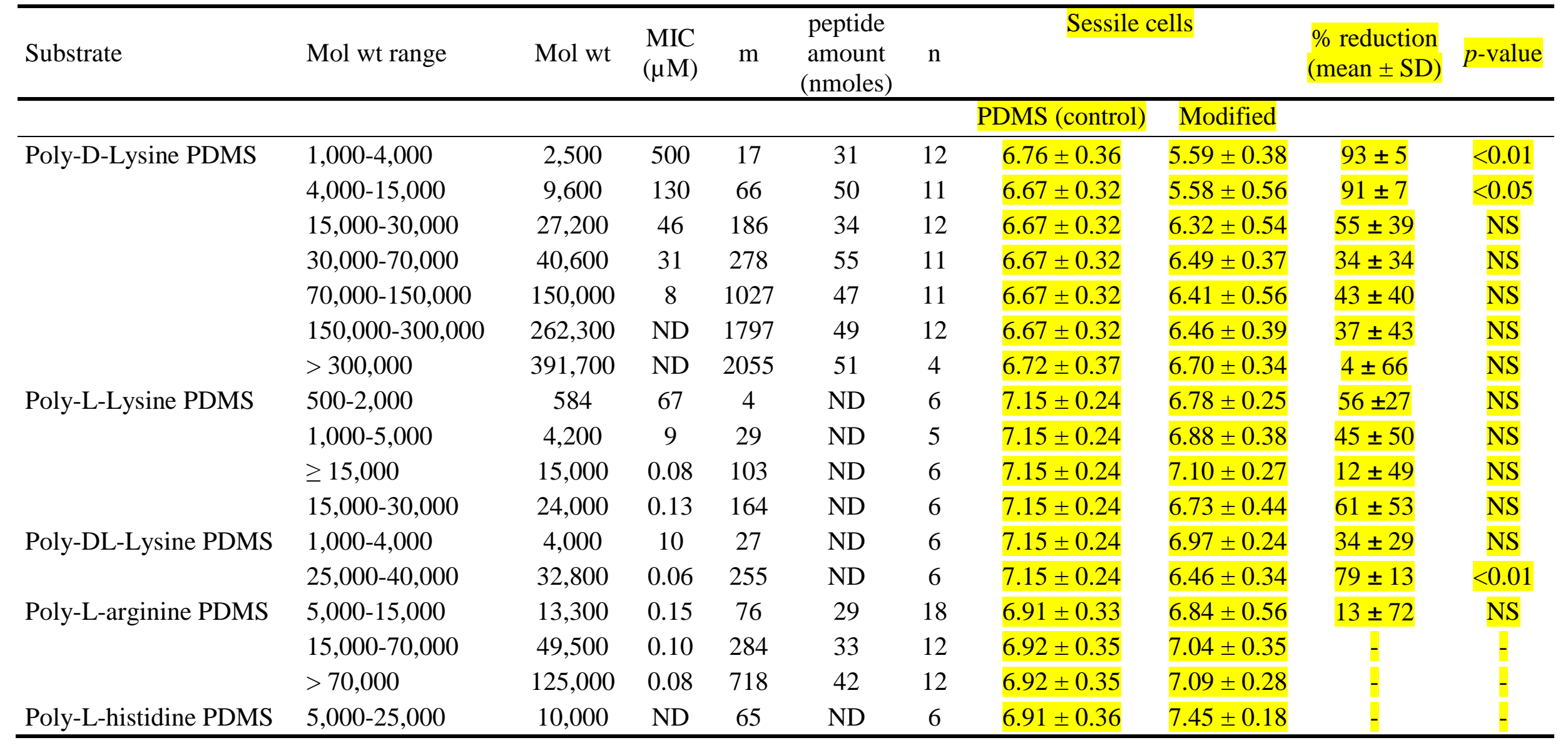

m, number of amino acids per peptide; n, number of disks tested; AFB, azido tetrafluorobenzoate; PDMS, polydimethylsiloxane; Mol wt, 5 molecular weight of most abundant molecule in mixture ; ND, not determined; peptide amount refers to total amount per disk; - : biofilm formation stimulated (i.e. cell counts on control disks lower than on modified disks); NS, not significant. 
Supplementary data - Figure 1. ATR image of unmodified PDMS (top) and PDMS modified with Dhvar-4 using AFB as interlinker. 